\title{
Triple oxygen isotopes in speleothems: A case study from Cave of the Bells, AZ, USA
}

\author{
Tyler E. Huth ${ }^{1 *}$, Benjamin H. PASSEY ${ }^{1}$, Julia E. \\ COLE $^{1}$, NAOMI R. LEVIN ${ }^{1}$
}

${ }^{1}$ University of Michigan, Earth and Environmental Sciences, 1100 North University Avenue, Ann Arbor, MI, 48109 *tehuth@umich.edu

Speleothems are commonly used as paleoclimate archives because they record climate-related variations in $\delta^{18} \mathrm{O}$ of precipitation. Although variability in speleothem $\delta^{18} \mathrm{O}$ is generally understood to relate to climate change, paleoclimate interpretations can be ambiguous because $\delta^{18} \mathrm{O}$ of precipitation relates to many factors, including precipitation seasonality, intensity, and source region. Evaporation can further modify water $\delta^{18} \mathrm{O}$ and, within a cave, kinetic effects during mineralization may cause imperfect recording of the $\delta^{18} \mathrm{O}$ of dripwater.

We address some of these problems by adding more information in the form of the triple isotope parameter $\Delta{ }^{17} \mathrm{O}$ (where $\Delta^{17} \mathrm{O}=\delta^{\prime 17} \mathrm{O}-0.528 \times \delta^{\prime 18} \mathrm{O}$ ). We use a model framework to identify which of three primary processes dominated speleothem $\Delta^{17} \mathrm{O}$ vs. $\delta^{18} \mathrm{O}$ data. In this framework, data defining a horizontal trend (slope $\approx 0$ per meg/\%o) results from equilibrium fractionation processes in the atmosphere (i.e., Rayleigh distillation; [1]); data defining a negative trend (slope $\leq-2$ ) results from changing aridity (i.e.., evaporation; [2]), and data defining a positive trend (slope $\approx$ 7; [3]) theoretically results from disequilibrium isotope effects in caves (e.g., drip rate).

Here, we tested interpretations of the previously investigated Cave of the Bells (COB), AZ, USA speleothem $\delta^{18} \mathrm{O}$ record. This record, which covers $50-10 \mathrm{ka}$, has been interpreted largely in terms of precipitation variability, and we therefore hypothesized that $\Delta^{17} \mathrm{O}$ vs. $\delta^{18} \mathrm{O}$ data would define a horizontal trend. The null hypotheses were that the slope would match either of the "kinetic" trends caused by evaporation or disequilibrium isotope effects (i.e., slope $=-2$ or +7 , respectively). Our samples define a trend of slope $=$ 0.1 in $\Delta^{17} \mathrm{O}$ vs. $\delta^{18} \mathrm{O}$ space that is distinct from the disequilibrium trend, but that is not resolvable from the evaporation trend. These results support previous precipitation-based interpretations of the COB record, but underscore the need for higher precision in $\Delta^{17} \mathrm{O}$ analyses to better resolve the effects of minor evaporation.

[1] Luz and Barkan, 2010, GCA vol. 74, p. 6276-6286

[2] Surma et al., 2018, Sci Rep vol. 8, 4972

[3] Guo and Zhou, 2019, GCA vol. 267, p. 196-226 